\title{
The National Emphysema Treatment Trial: Summary and Update
}

\author{
Melanie A. Edwards, $\mathrm{MD}^{\mathrm{a},}$, Stephen Hazelrigg, $\mathrm{MD}^{\mathrm{b}}$, \\ Keith S. Naunheim, MD ${ }^{\mathrm{C}}$
}

\section{KEYWORDS}

- Lung volume reduction surgery $\bullet$ Surgery for emphysema

- The National Emphysema Treatment $\bullet$ Trial $\bullet$ Emphysema

In medicine one often encounters a disease process for which there is no clear path that will lead to the best outcome for all patients. Surgery for severe emphysema is one such problem. End stage emphysema patients are ravaged by progressive destruction of their lung parenchyma; they live with severe and progressive dyspnea, which results in a poor functional status and quality of life. Optimal medical therapy for severe emphysema includes smoking cessation, bronchodilators, antibiotics, steroids as indicated, and long-term domiciliary oxygen therapy, the only medical intervention that had been demonstrated to decrease mortality. It would thus seem that a surgical intervention that could lengthen survival, relieve dyspnea and improve both function and quality of life would be in high demand. Lung volume reduction (LVR) surgery was demonstrated to provide just such results in many clinical series in the 1990's and yet today is a rarely performed operation. The reason for this is difficult to pinpoint but lung volume reduction surgery (LVRS) has had a long and controversial history.

\section{HISTORICAL BACKGROUND}

Surgical therapy for severe emphysema developed with the primary objectives of palliating these patients by producing improvement in symptoms and quality of life. Previous operations tackled the problem of emphysema by the formation of pneumoperitoneum, phrenic nerve paralysis, thoracoplasty, lung denervation and tracheal stabilization and fixation with little sustained benefit and today these techniques remain of historical interest only. ${ }^{1}$ The origins of lung volume reduction surgery stretch back to 1957 when Brantigan and Mueller first reported removing non-functional parts of the hyper-inflated lung parenchyma to improve dyspnea in emphysema patients. ${ }^{2}$ Unfortunately, their procedure was not widely adopted in spite of a $75 \%$ reported clinical improvement. This was due to a relatively high mortality rate of $18 \%$ and the inability (due to technologic limitations) to provide objective evidence of a significant benefit. $^{2}$ Renewed interest in LVRS for the treatment of emphysema developed in the early 1990s after Wakabayashi published encouraging early results with unilateral thoracoscopic laser parenchymal ablation of giant bullous emphysema. ${ }^{3}$ This garnered significant early enthusiasm and his updated analysis of 443 patients demonstrated an acceptable mortality rate of $4.8 \%$, and $87 \%$ of patients reported symptomatic improvements. ${ }^{4}$ These findings were not widely reproduced, and prospective data from Hazelrigg and colleagues showed only a modest $16 \%$ improvement in $\mathrm{FEV}_{1}$ with laser ablation that did not

\footnotetext{
a Division of Thoracic Surgery, Louisiana State University, 1542 Tulane Avenue, Room 749, New Orleans, LA 70112, USA

b Division of Cardiothoracic Surgery, Department of Surgery, Southern Illinois University, Post Office Box 19638, Springfield, IL 62794-9638, USA

c Department of Cardiothoracic Surgery, St. Louis University Health Sciences Center, 3635 Vista Avenue at Grand, Post Office Box 15250, St. Louis, MO 63110-0250, USA

* Corresponding author.

E-mail address: edwmelanie@gmail.com (M.A. Edwards).
} 
favorably compare with contemporary results from stapled resections. ${ }^{5}$ Joel Cooper's work helped to establish stapled resection as the procedure of choice for LVRS with his initial report of 20 patients in which he resected portions of both lungs via median sternotomy (MS). At a mean follow-up of 6.4 months, there were no deaths, and a significant $82 \%$ increase in $\mathrm{FEV}_{1}$, with more moderate improvements in the distance walked in 6 minutes, dyspnea and quality of life scores, and a decline in the number of patients requiring supplemental oxygen therapy. ${ }^{6}$ Even before the final publication of these findings, the fervor that was generated lead to the widespread adoption of LVRS at several centers. However, It is questionable whether the same careful patient selection and perioperative management was applied in all reported series as the resulting outcomes data yielded rather conflicting results. Although virtually all of these reports were favorable with morbidity and mortality ranging from $2.5 \%-10 \%,{ }^{7-13}$ a review of Medicare data from claims submitted between October 1995 and January 1996 showed much higher mortality rates of $14.4 \%$ and $23 \%$ at 3 and 12 months respectively. This report also documented very high rehospitalization rates and thus the Health Care Finance Administration (HCFA) decided to halt reimbursement for LVR unless and until definitive evidence was generated documenting efficacy. ${ }^{14}$ This refusal to reimburse for LVR in the absence of a "definitive" study prompted the creation of the National Emphysema Treatment Trial (NETT), a multi-institutional study sponsored jointly by the National Heart, Lung and Blood Institute (NHLBI), and the Center for Medicare and Medicaid Services (CMS, formerly HCFA) to develop prospective randomized data on the outcomes of lung volume reduction surgery. ${ }^{15}$

\section{NETT STUDY DESIGN}

The National Emphysema Treatment Trial (NETT) was designed to compare short and long-term outcomes of best medical therapy for emphysema with best medical therapy plus LVRS. The primary questions were whether there was a sustained survival benefit with surgery and if such intervention improved lung function, exercise capacity and quality of life. The development of reproducible selection criteria for surgery was yet another important goal of the study. The NETT investigators chose survival and maximum exercise capacity measured by cycle ergometry as the primary outcome measures. Secondary measures of outcome included quality of life, both general and disease specific cost-effectiveness, pulmonary function and gas exchange, oxygen requirement, 6 minute walk distance, cardiovascular measures and psychomotor functioning. Enrollment was limited to Medicare beneficiaries or those whose private insurance carrier would cover the costs of trial participation and CMS further stipulated that access to LVRS for Medicare patients could be obtained only through trial participation at one of the 17 designated clinical centers. The patient selection criteria included the presence of bilateral emphysema with severe airflow obstruction, hyperinflation on chest radiograph and the ability to participate in pulmonary rehabilitation. Eligible patients underwent comprehensive medical evaluation to exclude those who were at high risk for perioperative morbidity and mortality and those who had disease not suitable for LVRS or other circumstances that would make it unlikely for them to complete the trial. Clinical evaluations were performed at 6 and 12 months, then yearly thereafter. ${ }^{15}$

\section{TREATMENT REGIMENS}

Optimal medical therapy for emphysema was administered according to proposed guidelines from the American Thoracic Society and individual recommendations made by a NETT pulmonary physician. This included smoking cessation, bronchodilators, oxygen therapy, influenza and pneumococcal vaccinations, and pulmonary rehabilitation. All patients who were eligible for the study participated in pulmonary rehabilitation prerandomization for 6-10 weeks. The patients who had been randomized to medical therapy participated in intense pulmonary rehabilitation post-randomization for 8-9 weeks followed by long-term maintenance therapy over the trial duration. ${ }^{15}$

By consensus, bilateral stapled LVRS with excision of 20 to $35 \%$ of each lung was chosen as the surgical technique for the trial and the use of additional buttressing material was at the discretion of the individual surgeon. Bilateral LVRS had emerged as the standard of care in appropriate patients based on reports of operative morbidity/ mortality rates similar to that of unilateral LVRS but with better technique improvement in pulmonary spirometric testing and patient-reported quality of life. ${ }^{10,16}$ The surgical approach was by either median sternotomy or bilateral video-assisted thoracoscopic surgery (VATS), and in 6 centers, patients were randomized to either approach to try to identify any differences in outcome that may exist with the differing techniques. Patients randomized to the surgical arm of the study were expected to undergo operation within two weeks post randomization and resume pulmonary rehabilitation as soon as their clinical condition allowed. ${ }^{15}$ Overall 
results from the NETT were first reported in 2003 after 2 years and in 2006, Naunheim and colleagues reported the long-term follow-up of the surviving LVRS patients at a median of 4.3 years.

\section{SHORT TERM RESULTS}

From January 1998 to December 2002, 3777 patients were evaluated at the 17 clinical centers, and 1218 were randomized after completing 6 to 10 weeks of pulmonary rehabilitation. ${ }^{17}$ There were 608 patients assigned to surgery, and 610 to medical therapy. With the exception of a higher proportion of men in the medical therapy group, the base-line characteristics of both groups were similar (Table 1). ${ }^{17}$

\section{All Patients}

The primary outcome measures that the NETT intended to quantify were survival and change in exercise capacity. Exercise capacity was considered to be improved if there was a greater than 10 watt (W) increase above the post-rehabilitation baseline at the time of clinical evaluation. The median follow-up of patients was reported to be 29.2 months. Follow-up revealed a higher early mortality rate at 90 days in the surgery group $(7.9 \%)$ as compared with the medical therapy group (1.3\%), a result that was not unexpected considering the invasive nature of treatment in the surgical arm (Table 2). ${ }^{17}$ There was no difference in the early mortality when one compared the VATS and median sternotomy approaches. Yet, despite the higher early mortality in the surgical group, there was no difference in overall mortality between the groups during the shortterm follow-up (Fig. 1, panel A). There was, however, greater improvement experienced in functional status outcomes by patients in the surgical cohort when compared with their medical counterparts. This was evidenced by improvements in exercise capacity of more than $10 \mathrm{~W}$ in 28,22 and $15 \%$ of LVR patients compared with improvements in only 4,5 and $3 \%$ of medical patients after 6, 12 and 24 months (Fig. 2). When considering the secondary outcomes, the results also favored the group assigned to surgical therapy. They demonstrated a greater chance of having significant improvements in the 6 minute walk distance, percent of predicted $\mathrm{FEV}_{1}$ and dyspnea. Additionally surgical patients noted greater improvement in general and health related quality of life, which had been defined as a decrease of more than 8 points on the St. George's Respiratory Questionnaire (SGRQ) (see Fig. 2; Table 3). ${ }^{17}$

\section{High-Risk Subgroup}

As the trial progressed, ongoing evaluation of the mortality data was performed by the data and safety monitoring board every 3 months. From these interim analyses, in April 2001, a highrisk patient subgroup emerged that demonstrated an increased risk of overall mortality after LVRS, characterized by a low FEV 1 and a homogenous pattern of emphysema. ${ }^{18}$ Also associated with early increased mortality were a low $\mathrm{FEV}_{1}$ and a low carbon monoxide diffusing capacity (DLCO) (Fig. 3). Based on the resulting information in May 2001 investigators ceased enrollment of patients with a low $\mathrm{FEV}_{1}$ who had either a low carbon monoxide diffusing capacity, or homogenous emphysema on chest CT scan. All of the 140 patients in this group exhibited a very low $\mathrm{FEV}_{1}$ of no more than $20 \%$, and $87 \%$ of patients in this group had a carbon monoxide diffusing capacity of no more than $20 \%$ of their predicted value. On chest CT scanning, $94 \%$ of this group had a homogenous distribution of emphysema, and 41 patients met all three criteria. Among the 70 patients assigned to undergo surgery within this group, the overall mortality was 0.43 deaths per person-year versus 0.11 deaths per person-year in the 70 patients in medical arm. ${ }^{18}$ No patients in the medical therapy group died at 30 days, in stark contrast to the $16 \%$ mortality rate at 30 days in the surgery group (Table 4). Updated analysis of this group was performed at 2 years and the poor outcomes with surgery continued to persist (see Fig. 1, panel B). ${ }^{17}$ When analyzing the functional outcomes of the survivors from this subgroup at six months, the surgery group showed only small improvements in $\mathrm{FEV}_{1}$, exercise capacity and the distance walked in 6 minutes. For these high-risk patients with low $\mathrm{FEV}_{1}$ and either a low carbon monoxide diffusing capacity or homogenous emphysema, such small benefit was inconsequential given the prohibitive mortality risk and LVRS is not recommended for patients who meet these criteria. ${ }^{18}$

\section{Non-High-Risk Patients}

Exclusion of the patients in the high-risk subgroup left 1078 patients for analysis, and did not significantly alter the differences in mortality between the surgical group and the medical treatment group, although each group had a lower absolute mortality rate. ${ }^{17}$ Patients assigned to LVRS continued to demonstrate higher short-term mortality, with 30 -day rates of $2.2 \%$, compared with $0.2 \%$ in the medical group, and 90-day mortality rates of $5.2 \%$ compared with $1.5 \%$ in 
Table 1

Characteristics of all 1218 patients at baseline

\begin{tabular}{|c|c|c|}
\hline Characteristic & $\begin{array}{l}\text { Surgery Group } \\
(\mathrm{n}=608)\end{array}$ & $\begin{array}{l}\text { Medical-Therapy } \\
\text { Group }(n=610)\end{array}$ \\
\hline Age at randomization $-\mathrm{yr}$ & $66.5 \pm 6.3$ & $66.7 \pm 5.9$ \\
\hline Race or ethnic group - no. (\%) & - & - \\
\hline Non-Hispanic white & $581(96)$ & $575(94)$ \\
\hline Non-Hispanic black & $19(3)$ & $23(4)$ \\
\hline Other & $8(1)$ & $12(2)$ \\
\hline Sex-no. $(\%)^{\dagger}$ & - & - \\
\hline Female & $253(42)$ & $219(36)$ \\
\hline Male & $355(58)$ & $391(64)$ \\
\hline Distribution of emphysema on CT - no. $(\%)^{a}$ & - & - \\
\hline Predominantly upper lobe & $385(63)$ & $405(67)$ \\
\hline Predominantly non-upper lobe & $223(37)$ & $204(33)$ \\
\hline Heterogeneous & $330(54)$ & $336(55)$ \\
\hline Homogeneous & $278(46)$ & $274(45)$ \\
\hline Perfusion ratio ${ }^{b}$ & $0.30 \pm 0.21$ & $0.28 \pm 0.23$ \\
\hline Maximal workload - W & $38.7 \pm 21.1$ & $39.4 \pm 22.2$ \\
\hline Distance walked in $6 \mathrm{~min}-\mathrm{ft}^{\mathrm{c}}$ & $1216.5 \pm 312.6$ & $1219.0 \pm 316.0$ \\
\hline $\mathrm{FEV}_{1}$ after bronchodilator use - $\%$ of predicted value & $26.8 \pm 7.4$ & $26.7 \pm 7.0$ \\
\hline $\begin{array}{l}\text { Total lung capacity after bronchodilator } \\
\text { use - } \% \text { of predicted value }\end{array}$ & $128.0 \pm 15.3$ & $128.5 \pm 15.0$ \\
\hline $\begin{array}{l}\text { Residual volume after bronchodilator } \\
\text { use - } \% \text { of predicted value }\end{array}$ & $220.5 \pm 49.9$ & $223.4 \pm 48.9$ \\
\hline Carbon monoxide diffusing capacity - $\%$ of predicted value & $28.3 \pm 9.7$ & $28.4 \pm 9.7$ \\
\hline $\mathrm{PaO}_{2}-\mathrm{mmHg}$ & $64.5 \pm 10.5$ & $64.2 \pm 10.1$ \\
\hline $\mathrm{PaCO}_{2}-\mathrm{mmHg}$ & $43.3 \pm 5.9$ & $43.0 \pm 5.8$ \\
\hline Total score on St. George 's Respiratory Questionnaire ${ }^{\mathrm{d}}$ & $52.5 \pm 12.6$ & $53.6 \pm 12.7$ \\
\hline Average daily quality of well-being score ${ }^{* *}$ & $0.58 \pm 0.12$ & $0.56 \pm 0.11$ \\
\hline Total UCSD shortness of breath score ${ }^{\mathrm{e}}$ & $61.6 \pm 18.1$ & $63.4 \pm 18.6$ \\
\hline
\end{tabular}

Baseline measurements were obtained after rehabilitation but before randomization, except for the carbon monoxide diffusing capacity, which was measured before rehabilitation. Plus-minus values are means $\pm S D$. CT denotes computed tomography, $\mathrm{FEV}_{1}$ forced expiratory volume in one second, $\mathrm{PaO}_{2}$ partial pressure of arterial oxygen, and $\mathrm{PaCO}_{2}$ partial pressure of arterial carbon dioxide.

$P$ for homogeneity $=0.04$.

a Upper-lobe predominance of emphysema was judged subjectively by each center's radiologist, who described the distribution of disease as predominantly upper lobe, predominantly lower lobe, diffuse, or predominantly affecting superior segments of the lower lobes. The latter three choices were grouped as predominantly non-upper lobe. The classification of the emphysema as heterogeneous or homogeneous was based on subjective scores assigned by each center's radiologist to each of the three zones in each lung. Data on upper-lobe versus non-upper-lobe distribution were missing for one patient.

b The perfusion ratio is derived from the radionuclide perfusion scan. Each lung is divided into three zones, and a percentage of total perfusion is assigned to each zone. The ratio is calculated as the sum of the percentages assigned to the two upper zones divided by the sum of the percentages assigned to the four middle and lower zones.

c To convert values from feet to meters, divide by 3.28 .

d The St. George 's Respiratory Questionnaire is a 51-item questionnaire on the health-related quality of life with regard to respiratory symptoms that is completed by the patient; the total score ranges from 0 to 100 , with lower scores indicating better health-related quality of life.

e The University of California. San Diego (UCSD), Shortness of Breath Questionnaire is a 24-item questionnaire about dyspnea that is completed by the patient; the total score ranges from 0 to 120 , with lower scores indicating less shortness of breath.

the medical treatment arm (see Table 2). Early on, fewer surgical patients were living at home, as evidenced by a $28.1 \%$ rate of patients who were either hospitalized, living in a nursing facility or rehabilitation facility or unavailable for interview in spite of being alive. Such situations were observed in only $2.2 \%$ of patients in the medical group. Over the course of eight months, however, 


\begin{tabular}{|c|c|c|c|c|c|c|c|c|c|}
\hline \multicolumn{10}{|c|}{$\begin{array}{l}\text { Table } 2 \\
\text { Mortality among all patients and in subgroups }\end{array}$} \\
\hline \multirow{3}{*}{ Patients } & \multicolumn{3}{|c|}{ 90-Day Mortality } & \multicolumn{6}{|c|}{ Total Mortality } \\
\hline & \multirow{2}{*}{$\begin{array}{l}\text { Surgery Group } \\
\text { No. of Deaths/Total no. ( }\end{array}$} & \multirow{2}{*}{$\begin{array}{l}\text { Medical-Therapy } \\
\text { Group } \\
[95 \% \mathrm{Cl}])\end{array}$} & \multirow{2}{*}{$P$ Value } & \multicolumn{2}{|c|}{ Surgery Group } & \multicolumn{2}{|c|}{ Medical-Therapy Group } & \multirow{2}{*}{$\begin{array}{l}\text { Risk } \\
\text { Ratio } \\
-\end{array}$} & \multirow{2}{*}{$\frac{P \text { Value }}{-}$} \\
\hline & & & & $\begin{array}{l}\text { No. of } \\
\text { Deaths/ } \\
\text { Total no. }\end{array}$ & $\begin{array}{l}\text { No. of } \\
\text { Deaths/ } \\
\text { Person-yr }\end{array}$ & $\begin{array}{l}\text { No. of } \\
\text { Deaths/ } \\
\text { Total no. }\end{array}$ & $\begin{array}{l}\text { No. of } \\
\text { Deaths/ } \\
\text { Person-yr }\end{array}$ & & \\
\hline All patients & $48 / 608(7.9[5.9-10.3])$ & $8 / 610(1.3[0.6-2.6])$ & $<0.001$ & $157 / 608$ & 0.11 & $160 / 610$ & 0.11 & 1.01 & 0.90 \\
\hline High-risk $^{a}$ & $20 / 70(28.6[18.4-40.6])$ & $0 / 70(0[0-5.1])$ & $<0.001$ & $42 / 70$ & 0.33 & $30 / 70$ & 0.18 & 1.82 & 0.06 \\
\hline Other & $28 / 538(5.2[3.5-7.4])$ & $8 / 540(1.5[0.6-2.9])$ & 0.001 & $115 / 538$ & 0.09 & $130 / 540$ & 0.10 & 0.89 & 0.31 \\
\hline Subgroups ${ }^{\mathrm{b}}$ & - & & - & - & - & - & - & - & - \\
\hline \multicolumn{10}{|c|}{ Patients with predominantly upper-lobe emphysema } \\
\hline $\begin{array}{l}\text { Low exercise } \\
\text { capacity }\end{array}$ & $4 / 139(2.9[0.8-7.2])$ & $5 / 151(3.3[1.1-7.6])$ & 1.00 & $26 / 139$ & 0.07 & $51 / 151$ & 0.15 & 0.47 & 0.005 \\
\hline $\begin{array}{l}\text { High exercise } \\
\text { capacity }\end{array}$ & $6 / 206(2.9[1.1-6.2])$ & $2 / 213(0.9[0.1-3.4])$ & 0.17 & $34 / 206$ & 0.07 & $39 / 213$ & 0.07 & 0.98 & 0.70 \\
\hline \multicolumn{10}{|c|}{ Patients with predominantly non-upper-lobe emphysema } \\
\hline $\begin{array}{l}\text { Low exercise } \\
\text { capacity }\end{array}$ & $7 / 84(8.3[3.4-16.4])$ & $0 / 65(0[0-5.5])$ & 0.02 & $28 / 84$ & 0.15 & $26 / 65$ & 0.18 & 0.81 & 0.49 \\
\hline $\begin{array}{l}\text { High exercise } \\
\text { capacity }\end{array}$ & $11 / 109(10.1[5.1-17.3])$ & $1 / 111(0.9[0.02-4.9])$ & 0.003 & $27 / 109$ & 0.10 & $14 / 111$ & 0.05 & 2.06 & 0.02 \\
\hline
\end{tabular}

Mortality was measured from the date of randomization in both treatment groups. Total mortality rates are based on a mean follow-up of 29.2 months. $P$ values were calculated by Fisher 's exact test. Risk ratios are for the risk in the surgery group as compared with the risk in the medical-therapy group. A low base-line exercise capacity was defined as a postrehabilitation base-line maximal workload at or below the sex-specific 40th percentile ( $25 \mathrm{~W}$ for women and $40 \mathrm{~W}$ for men); a high-exercise capacity was defined as a workload above this threshold. Cl denotes confidence interval.

${ }^{\text {a }}$ High-risk patients were defined as those with a forced expiratory volume in one second (FEV 1 ) that was 20 percent or less of the predicted value and either homogeneous emphysema on computed tomography or a carbon monoxide diffusing capacity that was 20 percent or less of the predicted value.

${ }^{\mathrm{b}}$ High-risk patients were excluded from the subgroup analyses. For total mortality, $P$ for interaction $=0.004$; this $P$ value was derived from binary logistic-regression models with terms for treatment, subgroup, and the interaction between the two, with the use of an exact-score test with three degrees of freedom. Other factors that were considered as potential variables for the definition of subgroups included the base-line $\mathrm{FEV}_{1}$, carbon monoxide diffusing capacity, partial pressure of arterial carbon dioxide, residual volume, ratio of residual volume to total lung capacity, ratio of expired ventilation in one minute to carbon dioxide excretion in one minute, distribution of emphysema (heterogeneous versus. homogeneous), perfusion ratio, score for health-related quality of life, and Quality of Well-Being score; age; race or ethnic group; and sex. 
All Patients ( $\mathrm{N}=\mathbf{1 2 1 8})$

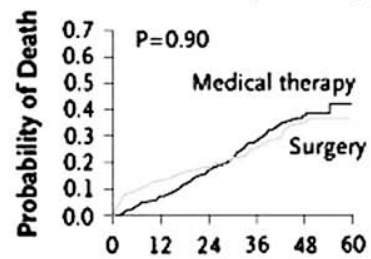

Months after Randomization

\section{No. at Risk}

$\begin{array}{llllll}\text { Surgery } & 608 & 491 & 376 & 233 & 74 \\ \text { Medical therapy } & 610 & 527 & 384 & 224 & 70\end{array}$
High-Risk Patients $(\mathrm{N}=140)$

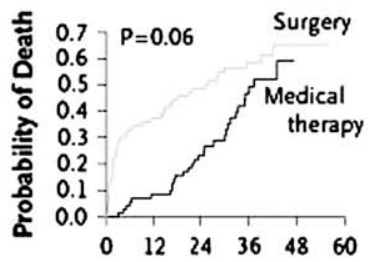

Months after Randomization

\section{No. at Risk}

$\begin{array}{llllll}\text { Surgery } & 70 & 44 & 36 & 19 & 4\end{array}$
Non-High-Risk Patients ( $N=1078$ )

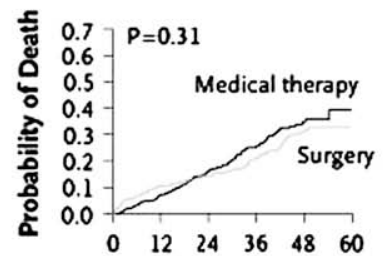

Months after Randomization

\section{No. at Risk}

$\begin{array}{llllll}\text { Surgery } & 538 & 447 & 340 & 214 & 70\end{array}$ Medical therapy $\begin{array}{llllll}540 & 463 & 339 & 204 & 70\end{array}$

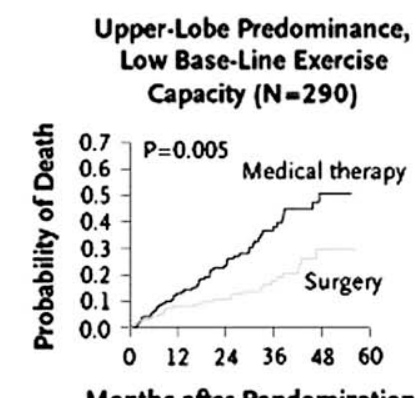

\section{Months after Randomization}

No. at Risk $\begin{array}{llllll}\text { Surgery } & 139 & 121 & 93 & 61 & 17 \\ \text { Medical therapy } & 151 & 120 & 85 & 43 & 13\end{array}$

Non-Upper-Lobe Predominance, Low Base-Line Exercise Capacity $(\mathrm{N}=149)$

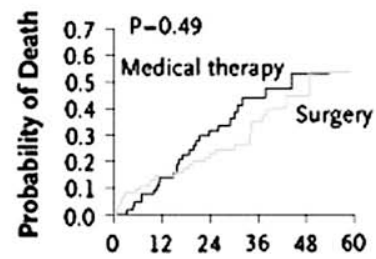

Months after Randomization

\section{No. at Risk}

$\begin{array}{llllll}\text { Surgery } & 84 & 67 & 52 & 28 & 6 \\ \text { Medical therapy } & 65 & 55 & 36 & 17 & 5\end{array}$
Upper-Lobe Predominance, High Base-Line Exercise Capacity $(\mathrm{N}=419)$

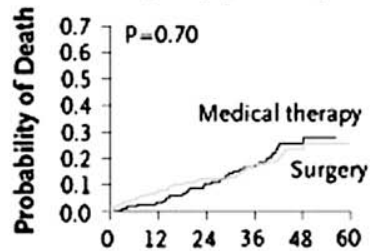

Months after Randomization

\section{No. at Risk}

$\begin{array}{llllll}\text { Surgery } & 206 & 176 & 124 & 82 & 35\end{array}$

$\begin{array}{llllll}\text { Medical therapy } & 213 & 192 & 149 & 104 & 35\end{array}$

\section{Non-Upper-Lobe Predominance, High Base-Line Exercise Capacity $(\mathrm{N}=220)$}

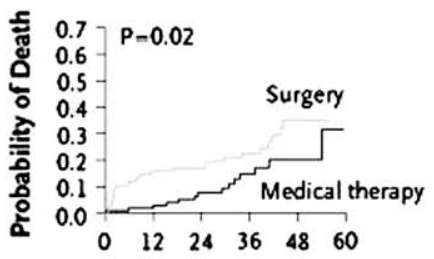

Months after Randomization

No. at Risk

$\begin{array}{llllll}\text { Surgery } & 109 & 83 & 71 & 43 & 12 \\ \text { Medical therapy } & 111 & 96 & 69 & 40 & 17\end{array}$

Fig. 1. The National Emphysema Treatment Trial (NETT): summary and update. Kaplan-Meier estimates of the probability of death as a function of the number of months after randomization. $P$ values were derived by Fisher's exact test for the comparison between groups over a mean follow-up period of 29.2 months. High-risk patients were defined as those with a forced expiratory volume in one second that was 20 percent of less of the predicted value, and either homogeneous emphysema or a carbon monoxide diffusing capacity that was 20 percent of less of the predicted value. A low baseline exercise capacity was defined as a maximal workload at or below the sex-specific 40th percentile ( $25 \mathrm{~W}$ for women and $40 \mathrm{~W}$ for men); a high exercise capacity was defined as a workload above this threshold. This was an intention-to-treat analysis. (From Fishman A, Martinez F, Naunheim K, et al. A randomized trial comparing lung-volume-reduction surgery with medical therapy for severe emphysema. N Engl J Med 2003;348:2059-73; with permission. Copyright @ 2003, Massachusetts Medical Society.)

this difference dissipated such that $3.3 \%$ of the surgical patients and $3.7 \%$ of medical patients were institutionalized, a difference that was not significant. ${ }^{17}$
Also, over time the observed mortality differences ceased to be significant. In the non-highrisk group of patients, the total mortality rates of 0.09 deaths per person-year in the surgery group, 

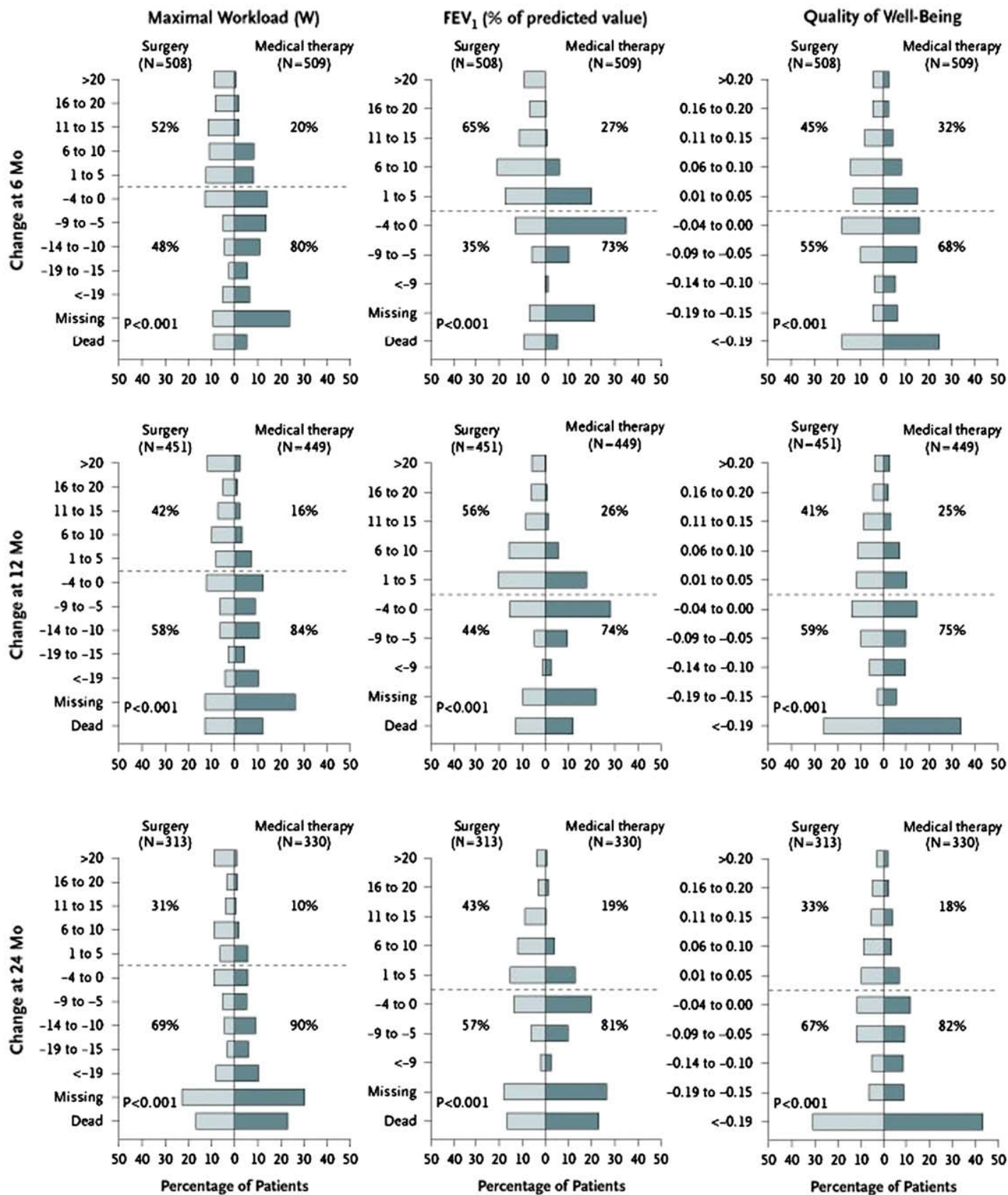

Fig. 2. Histograms of changes from baseline in exercise capacity (maximal workload), percentage of the predicted value for forced expiratory volume in one second $\left(\mathrm{FEV}_{1}\right)$, and quality of life (quality of well-being score) after 6 , 12, and 24 months of follow-up. Baseline measurements were performed after pulmonary rehabilitation. Patients previously identified as high-risk were excluded. Patients who were too ill to complete the procedure or who declined to complete the procedure but did not explain why were included in the "missing" category. For the quality of well-being score, patients who died were assigned a score of 0 on the questionnaire for the visit. $P$ values were determined by the Wilcoxon rank-sum test. The degree to which the bars are shifted to the upper left of the chart indicates the degree of relative benefit of lung-volume-reduction surgery over medical treatment. The percentage shown in each quadrant is the percentage of patients in the specified treatment group with a change in the outcome falling into that quadrant. This was an intention-to-treat analysis. (From Fishman A, Martinez F, Naunheim $K$, et al. A randomized trial comparing lung-volume-reduction surgery with medical therapy for severe emphysema. N Engl J Med 2003;348:2059-73; with permission. Copyright @ 2003, Massachusetts Medical Society.) 
Table 3

Improvement in exercise capacity and health-related quality of life at 24 months

\begin{tabular}{|c|c|c|c|c|c|c|c|c|}
\hline Patients & \multicolumn{4}{|c|}{ Improvement in Exercise Capacity } & \multicolumn{4}{|c|}{ Improvement in Health-Related Quality of Life } \\
\hline All patients & $54 / 371(15)$ & $10 / 378(3)$ & 6.27 & $<0.001$ & $121 / 371(33)$ & $34 / 378(9)$ & 4.90 & $<0.001$ \\
\hline High-risk $^{a}$ & $4 / 58(7)$ & $1 / 48(2)$ & 3.48 & 0.37 & $6 / 58(10)$ & $0 / 48$ & - & 0.03 \\
\hline Other & $50 / 313(16)$ & $9 / 330(3)$ & 6.78 & $<0.001$ & $115 / 313(37)$ & $34 / 330(10)$ & 5.06 & $<0.001$ \\
\hline Subgroups $^{\mathrm{b}}$ & & & & & & & & \\
\hline $\begin{array}{l}\text { Low exercise } \\
\text { capacity }\end{array}$ & $25 / 84(30)$ & $0 / 92$ & - & $<0.001$ & $40 / 84(48)$ & $9 / 92(10)$ & 8.38 & $<0.001$ \\
\hline $\begin{array}{l}\text { High exercise } \\
\text { capacity }\end{array}$ & $17 / 115(15)$ & $4 / 138(3)$ & 5.81 & 0.001 & $47 / 115(41)$ & $15 / 138(11)$ & 5.67 & $<0.001$ \\
\hline \multicolumn{9}{|l|}{$\begin{array}{l}\text { Predominantly } \\
\text { non-upper-lobe } \\
\text { emphysema }\end{array}$} \\
\hline $\begin{array}{l}\text { High exercise } \\
\text { capacity }\end{array}$ & $2 / 65(3)$ & $2 / 59(3)$ & 0.90 & 1.00 & $10 / 65(15)$ & $7 / 59(12)$ & 1.35 & 0.61 \\
\hline
\end{tabular}

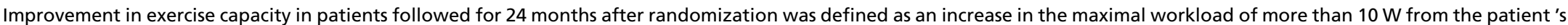

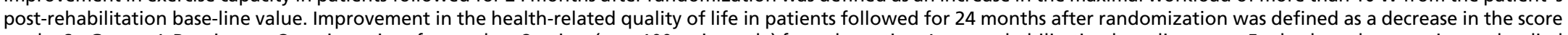

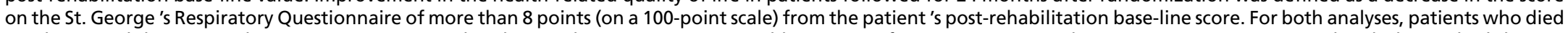

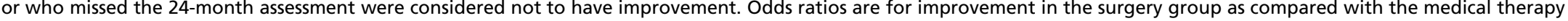

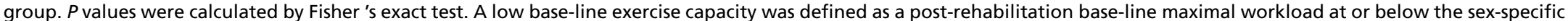
40th percentile ( $25 \mathrm{~W}$ for women and $40 \mathrm{~W}$ for men); a high exercise capacity was defined as a workload above this threshold.

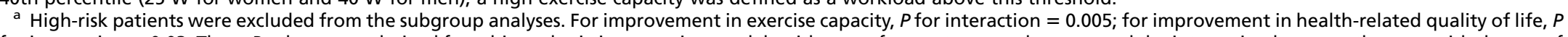

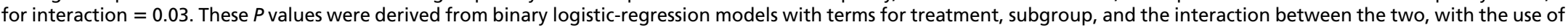

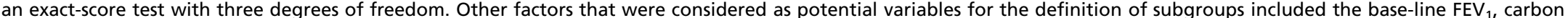

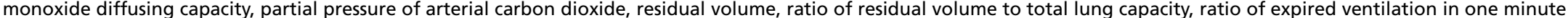

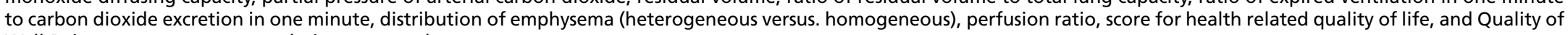
Well-Being score; age; race or ethnic group; and sex.

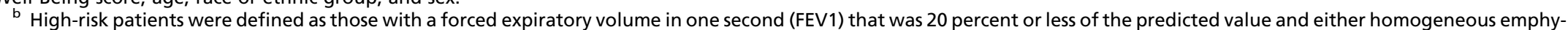
sema on computed tomography or a carbon monoxide diffusing capacity that was 20 percent or less of the predicted value. 


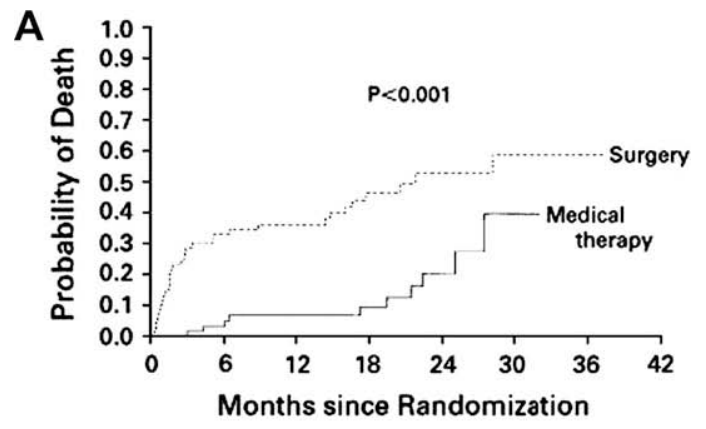

No. AT RISK

$\begin{array}{llllllll}\text { Surgery } & 70 & 45 & 37 & 22 & 12 & 6 & 2 \\ \text { Medical therapy } & 70 & 55 & 44 & 31 & 14 & 2 & 0\end{array}$

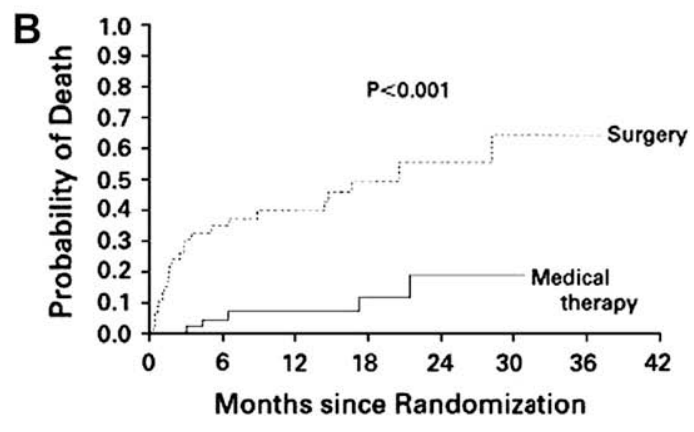

No. AT RISK

$\begin{array}{llllllll}\text { Surgery } & 46 & 29 & 21 & 12 & 7 & 3 & 1 \\ \text { Medical therapy } & 48 & 36 & 28 & 17 & 9 & 1 & 0\end{array}$

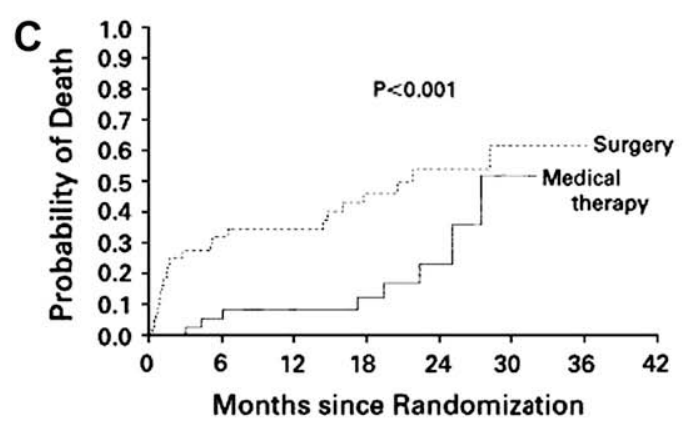

No. AT RISK

$\begin{array}{llllllll}\text { Surgery } & 44 & 29 & 25 & 17 & 9 & 4 & 1 \\ \text { Medical therapy } & 43 & 33 & 26 & 21 & 8 & 2 & 0\end{array}$

Fig. 3. Kaplan-Meier estimates of the probability of death among high-risk patients, according to whether they were randomly assigned to undergo lung-volumereduction surgery or receive medical therapy. This intention-to-treat analysis shows the overall results for the high-risk group $(A)$, the subgroup of patients with an $\mathrm{FEV}_{1}$ that was no more than 20 percent of their predicted value and a homogeneous distribution of emphysema on CT scanning $(B)$, and the subgroup of patients with an $\mathrm{FEV}_{1}$ that was no more than 20 percent of their predicted value $(C)$. For each analysis the difference between groups was significant $(P<.001, P<.001$, and $P=.005$, respectively) by the log-rank test. (From The National Emphysema Treatment Trial Research Group. Patients at high risk of death after lung-volume-reduction surgery. N Engl J Med 2001;345:1075-83; with permission. Copyright (c) 2001, Massachusetts Medical Society.)

and 0.10 deaths per person-year in the medical therapy group were not significantly different at 29 months (see Fig. 1, panel C). As similarly demonstrated in the overall analysis, there were more favorable results with surgery with respect to the changes in exercise capacity, distance walked in 6 minutes, percent predicted $\mathrm{FEV}_{1}$, quality of life and degree of dyspnea at 6, 12 and 24 months (see Fig. 2; Table 3). ${ }^{17}$ Patients who were not designated as being at high risk for mortality could reasonably expect some functional gains and improvements in health-related quality of life in the short term, however they did not gain a significant survival benefit.

\section{Preoperative Predictors of Outcome Among Non-High-Risk Patients}

Throughout the trial, investigators and the data and safety monitoring board analyzed groups of patients who may possibly derive so much benefit from the procedure as to mandate their removal from the trial. No such group emerged, and in the short-term the only preoperative factors predictive of mortality that gained significance were the presence or absence of upper-lobe predominant emphysema on chest $\mathrm{CT}$, and the level of baseline exercise capacity. ${ }^{17}$ The cutoff point for defining low baseline exercise capacity that predicted the differential risk of death was the 40th percentile, $25 \mathrm{~W}$ for women, and $40 \mathrm{~W}$ for men. Only the distribution of emphysema could be related to improvements in the maximal achievable workload at 24 months and none of the multiple baseline factors examined predicted improvements in health related quality of life. Thus, using these 2 characteristics (emphysema distribution and exercise capacity), patients were subdivided into 4 groups to further characterize the risks and benefits from LVRS, producing strong evidence of differential effects of these groupings on the risk of death, and changes in exercise capacity at 24 months. ${ }^{17}$

\section{Upper-Lobe Disease and Low Baseline Exercise Capacity}

There were a total of 290 patients identified who had both upper-lobe disease and low baseline exercise capacity. Patients in this sub-group who underwent LVRS had a significant survival advantage in the short-term with 0.47 risk ratio of death (see Fig. 1, panel D), and $30 \%$ of these surgical patients demonstrated improvements in the maximum workload relative to $0 \%$ of medical therapy patients, a difference that was significant. Surgical patients were also more likely than medically treated patients to have an 8-point 


\section{Table 4}

Mortality rates among high-risk patients

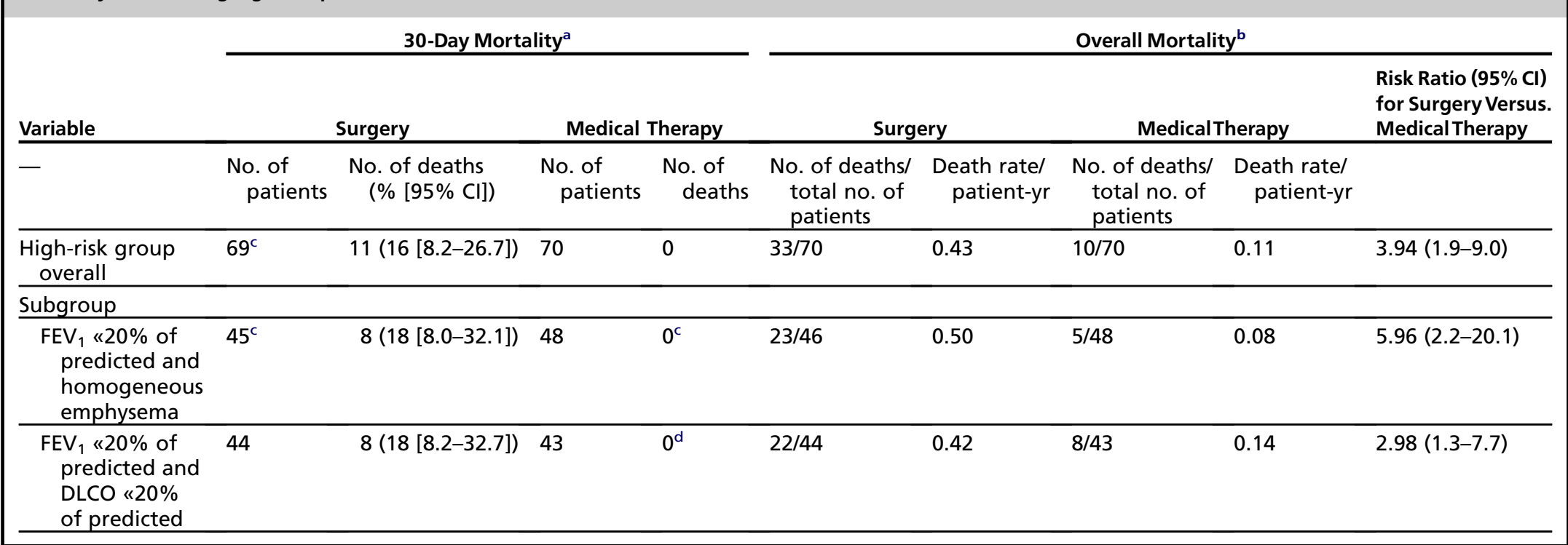

High-risk patients are those with a forced expiratory volume in one second $\left(\mathrm{FEV}_{1}\right)$ that was no more than 20 percent of their predicted value and either a homogeneous distribution of emphysema on CT scanning or a carbon monoxide diffusing capacity (DLCO) that was no more than 20 percent of their predicted value. A total of 41 patients had all three risk

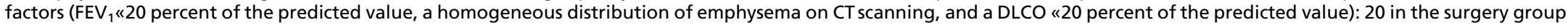
and 21 in the medical-therapy group. Five of the 20 patients in the surgery group who had all three factors died within 30 days after surgery. Cl denotes confidence interval.

$P<.001$ for the comparison with the surgery group.

$P=.002$ for the comparison with the surgery group.

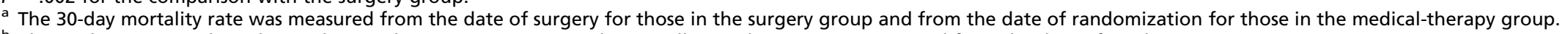

b The analysis was conducted according to the intention to treat. The overall mortality rate was measured from the date of randomization.

c One patient in the high-risk subgroup who was assigned to surgery declined to undergo it and was excluded from this analysis.

d $P=.006$ for the comparison with the surgery group. 
improvement in the SGRQ score at 24 months (48\% versus $10 \%$ ) (see Table 3 ). ${ }^{17}$

\section{Upper-Lobe Disease and High Baseline Exercise Capacity}

For the 419 patients with upper-lobe disease and high exercise capacity, LVRS did not show any survival advantages when compared with medical therapy (see Fig. 1, panel E). ${ }^{13}$ However, more of these patients improved greater than $10 \mathrm{~W}$ in the maximal workload achieved, and a higher proportion also had quality of life improvement with a greater than eight-point decrease in the SGRQ at 24 months (see Table 3). ${ }^{17}$

\section{Non-Upper-Lobe Disease and Low Baseline Exercise Capacity}

Within the group of 149 patients with non-upperlobe disease and low exercise capacity there was no difference in the risk of death between the surgical and medical therapy groups (see Fig. 1, panel F), nor were there significant relative improvements in exercise capacity. There was, however, significant improvement in health related quality of life in the LVRS patients observed at 24 months (37\% versus 7\%) (see Table 3). ${ }^{17}$

\section{Non-Upper Lobe Disease and High Baseline Exercise Capacity}

Patients who had non-upper lobe predominant disease and high exercise capacity and underwent LVRS had a higher risk of death than those in the medical therapy group, with a risk ratio of 2.06 (see Fig. 1, panel G and Table 2). ${ }^{17}$ Additionally, the likelihood of improvement in the maximal workload and health related quality of life scores were similarly low in both the surgical and medical therapy groups at $3 \%$ each (see Table 3). ${ }^{17}$ In spite of the unfavorable results in this group of patients, identifying and defining their characteristics was one of the important secondary goals of the trial.

Thus, when considering the NETT primary outcome measures of survival and changes in exercise capacity, the most convincing advantages of LVRS over medical therapy were found in those patients who had both upper-lobe predominant disease and low baseline exercise capacity. There was clearly no benefit from surgery in patients with non-upper-lobe disease and high exercise capacity, a subgroup that demonstrated a higher risk of death. In the remaining two subgroups, although there was no difference in survival between LVRS and medical therapy, there were differences in functional outcomes. Lung volume reduction surgery produced improvements in both baseline exercise capacity and health related quality of life in the subgroup with upper-lobe predominant disease and high exercise capacity. The non-upper-lobe predominant disease and low exercise capacity subgroup experienced no exercise improvement with LVRS, but did demonstrate a benefit in health-related quality of life at 24 months. ${ }^{17}$

\section{OPERATIVE MORBIDITY AND MORTALITY}

A more focused analysis of the morbidity and mortality data from the NETT was undertaken by Naunheim and colleagues, as they examined the 511 non-high-risk patients who underwent LVRS, with the intent of identifying predictors of operative mortality, and pulmonary and cardiovascular morbidity. Due to the fragile nature of patients with severe emphysema it was important to understand the "clinical cost" at which the benefits derived from LVRS were obtained. The 90-day mortality from all causes was chosen to represent the most accurate risk of mortality as many of these patients had prolonged stays in acute care hospitals and chronic care facilities. They found an operative mortality of $5.5 \%$ in this non-high risk surgical cohort, and an incidence of major pulmonary and cardiac morbidity of $29.8 \%$ and $20 \%$ respectively. As suggested in the NETT subgroup analysis, the only significant prognostic factor for operative mortality was the presence of non-upper-lobe predominant disease on chest CT as characterized by a radiologist. Major pulmonary morbidity was predicted by age, percent-predicted $\mathrm{FEV}_{1}$, and percent-predicted DLCO. Patients with advanced age, oral steroid use and non-upper-lobe predominant disease by quantitative image analysis were found to be at higher risk for cardiovascular complications. ${ }^{19}$ The relatively low mortality rates demonstrated in the NETT trial spoke to the critical importance of careful patient selection, preoperative optimization of functional status and attention to perioperative care when selecting and managing patients undergoing LVRS.

\section{Median Sternortomy Versus Vats}

The development of contemporary surgical therapy for severe emphysema began with Joel Cooper's revival of lung volume reduction surgery in 1994. Unlike Brantigan in the 1950s, Cooper approached his bilateral pulmonary resections by median sternotomy. ${ }^{3}$ The concurrent development and increasing application of video-assisted thoracoscopic surgery (VATS) during this same time period made it a viable alternative approach to median sternotomy in the performance of LVR 
procedure. While evidence mounted regarding the benefit of a bilateral over a unilateral LVRS, ${ }^{10,16}$ the optimal operative approach had not been similarly elucidated. A secondary goal of the NETT was to examine and compare the outcomes of median sternotomy compared with VATS for mortality, morbidity and functional outcome. Across the NETT centers, 6 sites performed both median sternotomy and VATS and their patients were randomized to either technique. In the remaining 11 centers VATS LVR only was performed at 3 , and median sternotomy only at 8 . In the randomized patient subset, there were no intraoperative deaths in either group, and the 30 and 90-day mortality rates were similar. When considering the entire surgical cohort (randomized and otherwise) there were no significant differences with regards to complications or functional outcomes. The only difference noted was that the use of median sternotomy was associated with a longer length of stay and higher operative costs at 6 months when compared with VATS. This difference that was maintained across non-randomized and randomized comparison groups. ${ }^{20}$

\section{LONG-TERM OUTCOMES}

Would the benefits derived from surgery last? Important concerns regarding the durability of the survival benefits, and improvements in functional status were addressed as the NETT investigators continued to monitor patients after the completion of the initial trial. There are four subgroups of patients defined by the presence or absence of upper-lobe predominant disease in combination with baseline exercise capacity (high or low).

\section{All Patients}

Seventy percent of surviving patients participated in the extension of follow up, and $76 \%$ participated in the mailed quality of life data collection. At a median follow-up period of 4.3 years, 283 patients assigned to LVRS and 324 assigned to medical therapy had died. From this data, a significant survival advantage eventually emerged in the entire surgical group with 0.11 deaths per personyear compared with the medical group in which there were 0.13 deaths per person-year (Fig. 4, panel A). ${ }^{21}$ In addition to the survival benefit, improvements in exercise capacity of more than $10 \mathrm{~W}$ above the post-rehabilitation baseline were seen in a significantly higher number of surgical patients relative to medical patients at all time points up to 3 years, with improvements seen in $23 \%, 15 \%$ and $9 \%$ of LVRS patients, compared with $5 \%, 3 \%$ and $1 \%$ of medical patients at 1,2 and 3 years (Fig. 5, panel A). Similarly, improvements in health-related quality of life were significantly better in the surgical group up to 5 years with $40 \%, 32 \%, 20 \%, 10 \%$ and $13 \%$ of LVRS patients demonstrating a greater than 8 -point decrease in the SGRQ, versus $9 \%, 8 \%$, $8 \%, 4 \%$ and $7 \%$ improvements in the medical group at 1, 2, 3, 4, and 5 years (Fig. 6, panel A). ${ }^{21}$

\section{High-Risk Patients}

As seen in the 2-year follow-up, the high-risk subgroup continued to demonstrate a substantial mortality risk from LVRS with no derived functional benefit.

\section{Non-High Risk Patients}

Updated analysis of the 1078 non-high-risk patients also revealed a significant survival advantage for LVRS, with mortality rates of 0.10 deaths per person-year in the LVRS group, and 0.12 deaths per person-year in the medical group (see Fig. 4, panel B). Although exercise capacity improved with LVRS and the benefit over medical therapy was sustained, patients in both medical and surgical groups experienced gradual declines over a 3-year period (see Fig. 5, panel B). Measures of health related quality of life were also better for LVRS patients in this updated analysis with sustained, significant improvements in SGRQ in $43 \%, 35 \%, 22 \%, 12 \%$ and $15 \%$ of LVRS patients at $1,2,3,4$, and 5 years respectively, while only $10 \%, 9 \%, 8 \%, 5 \%$ and $7 \%$ of medical patients derived any benefit over the same time period (see Fig. 6, panel B). ${ }^{21}$

\section{Upper-Lobe Emphysema with Low Exercise Capacity}

In the 290 patients with upper-lobe disease and low exercise capacity, a survival advantage for LVRS was maintained throughout the 5 years of follow up (see Fig. 4, panel C). Lung volume reduction surgery patients also continued to demonstrate more significant improvements in exercise capacity (see Fig. 5, panel C) and SGRQ score with surgical therapy over the same time period.

\section{Upper Lobe and High Exercise Capacity}

The cohort of 419 patients with upper-lobe emphysema and high exercise capacity continued to see no survival benefit from LVRS, however they still enjoyed better functional outcomes as evidenced by a significantly greater proportion of patients who had improved exercise capacity (see Fig. 5, panel D) and SGRQ scores (see Fig. 6, panel D) with surgery. 

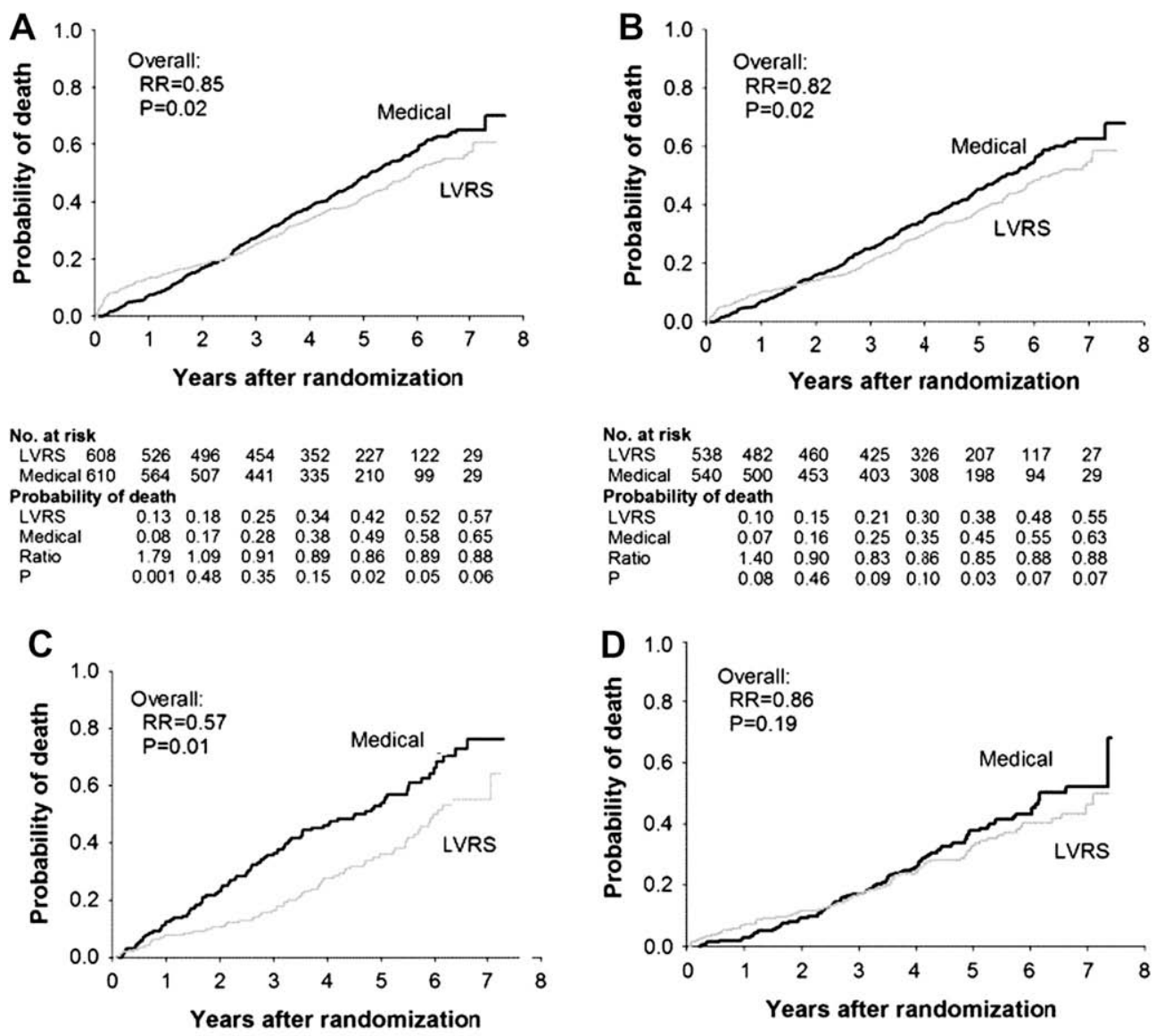

\begin{tabular}{|c|c|c|c|c|c|c|c|c|}
\hline \multicolumn{9}{|c|}{ No. at risk } \\
\hline LVRS & 139 & 127 & 123 & 115 & 88 & 57 & 32 & 6 \\
\hline Medical & 151 & 131 & & 95 & 70 & 47 & 16 & \\
\hline \multicolumn{9}{|c|}{ Probability of death } \\
\hline LVRS & & 0.09 & 0.12 & 0.17 & 0.28 & 0.3 & 0.5 & 0.5 \\
\hline & & & & 0.3 & 0.4 & & & 0.7 \\
\hline & & & 0.48 & 0.47 & 0.59 & 0.67 & 0.78 & 0.7 \\
\hline P & & 0 & 0.01 & 0.001 & 0.001 & 0.003 & 0.04 & 000 \\
\hline
\end{tabular}

$\begin{array}{lrllllll}\begin{array}{l}\text { No.at risk } \\ \text { LVRS 206 }\end{array} & 191 & 181 & 170 & 133 & 80 & 52 & 17 \\ \begin{array}{l}\text { Medical 213 } \\ \text { Probability of death }\end{array} & 206 & 192 & 176 & 143 & 92 & 55 & 17 \\ \text { LVRS } & 0.07 & 0.12 & 0.17 & 0.25 & 0.33 & 0.40 & 0.46 \\ \text { Medical } & 0.03 & 0.10 & 0.17 & 0.23 & 0.38 & 0.43 & 0.52 \\ \text { Ratio } & 2.21 & 1.23 & 1.01 & 0.94 & 0.87 & 0.94 & 0.89 \\ \text { P } & 0.07 & 0.46 & 0.98 & 0.71 & 0.32 & 0.61 & 0.39\end{array}$

Fig. 4. Kaplan-Meier estimates of the cumulative probability of death as a function of years after randomization to lung volume reduction surgery (LVRS, gray line) or medical treatment (black line) for $(A)$ all patients and $(B-D)$ non-high-risk and upper-lobe-predominant subgroups of patients. The $P$ value is from the Fisher exact test for difference in the proportions of patients who died during the 4.3 years (median) of follow-up. Shown below each graph are the numbers of patients at risk, the Kaplan-Meier probabilities, the ratio of the probabilities (LVRS:Medical), and $P$ value for the difference in these probabilities. This is an intention-to-treat analysis. $(A)$ All patients $(N=1218)$. (B) Non-high-risk patients $(n=1078)$. (C) Upper-lobe-predominant and low baseline exercise capacity $(n=290)$. (D) Upper-lobe-predominant and high exercise capacity $(n=419)$. (RR = relative risk.) (From Naunheim KS, Wood DE, Mohsenifar Z, et al. Long-term follow-up of patients receiving lung-volumereduction surgery versus medical therapy for severe emphysema by the National Emphysema Treatment Trial research group. Ann Thorac Surg 2006;82:431-43; with permission.)

\section{Non-Upper Lobe with High Exercise Capacity}

Initially these patients were found to only have significant improvements in health-related quality of life with LVRS compared with medical therapy at two years with no benefit in either survival or exercise capacity. Unfortunately, even this modest benefit disappeared by 3 years, leaving no advantage to LVRS for these patients.

\section{Non-Upper Lobe with Low Exercise Capacity}

These patients who at two years failed to demonstrate any benefit from LVRS were found not to gain any benefit long term from the LVRS procedure with regard to survival, quality of life, or exercise capacity. ${ }^{21}$

Although there were declines in most of the absolute outcome measures in both treatment 
A
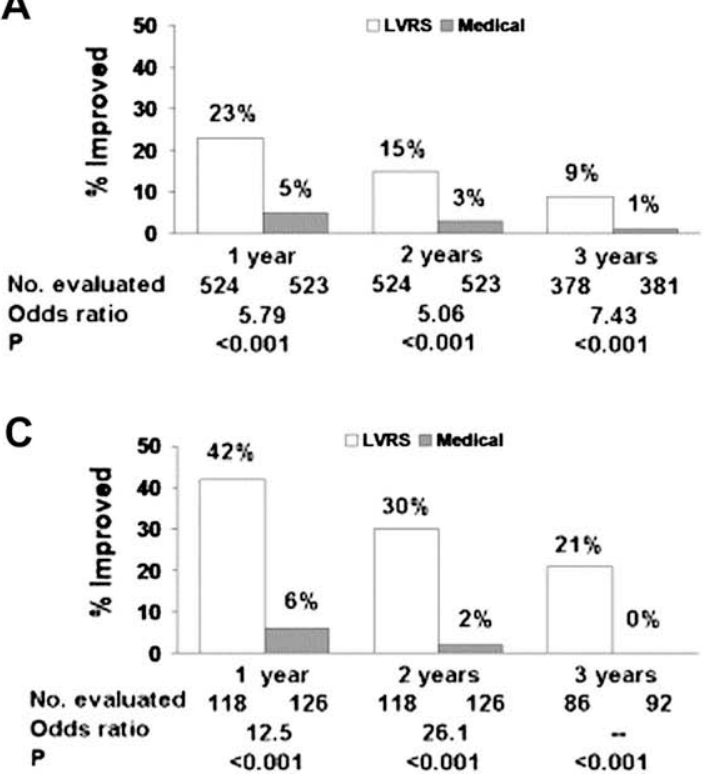

B
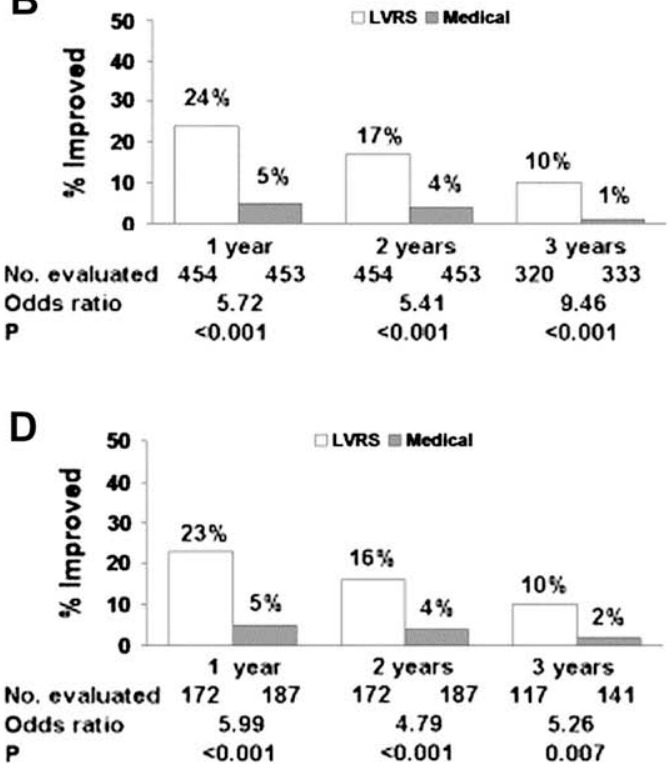

Fig. 5. Improvement in exercise capacity (increase in maximum work of $>10 \mathrm{~W}$ above the patient 's postrehabilitation baseline) at 1, 2, and 3 years after randomization to lung volume reduction surgery (LVRS, open box) or medical treatment (filled box) for $(A)$ all patients and $(B-D)$ non-high-risk and upper-lobe-predominant subgroups of patients. Shown below each graph are the numbers of patients evaluated, the odds ratio for improvement (LVRS:Medical), and the Fisher exact $P$ value for difference in proportion improved. Patients who died or who did not complete the assessment were considered not improved. This is an intention-to-treat analysis. (A) All patients $(N=1218)$. (B) Non-high-risk patients $(n=1078)$. (C) Upper-lobe-predominant and low baseline exercise capacity $(n=290)$. (D) Upper-lobe-predominant and high exercise capacity $(n=419)$. (From Naunheim KS, Wood DE, Mohsenifar Z, et al. Long-term follow-up of patients receiving lung-volume-reduction surgery versus medical therapy for severe emphysema by the National Emphysema Treatment Trial research group. Ann Thorac Surg 2006;82:431-43; with permission.)

groups over time, LVRS patients were significantly better off than their medical counterparts at each time period with regard to exercise capacity and health related quality of life.

\section{COST EFFECTIVENESS}

During the development and enrollment phases of the NETT, emphysema was estimated to affect approximately 2 million Americans, ${ }^{22}$ and more recent estimates suggest that the incidence has essentially doubled to approximately 4 million Americans. ${ }^{23}$ Given the chronic, debilitating nature of emphysema, and its growing prevalence, the economic impact of treating these patients, either with surgical or medical therapy, has the potential to be quite significant. New therapies need to be evaluated within this context, in addition to examining the more traditional outcome measures such as survival, functional gains and quality of life estimates. As such, within the NETT, separate, concurrent prospective analysis of the cost-effectiveness of LVRS was conducted to quantify the actual economic impact of LVRS using costs per quality-adjusted life years gained. ${ }^{24}$ At both the short, and long-term follow-up, LVRS was found to be costly relative to medical therapy, even when the high-risk subgroup had been excluded. ${ }^{25,26}$ However, at long-term follow-up the cost-effectiveness of LVRS was more favorable, especially when compared with standard surgical therapies for other conditions. In spite of this, the fact remains that LVRS is still perceived by many as carrying a prohibitive expense. This is possibly one of the reasons that, in spite of CMS approval for LVRS, the procedure has not experienced widespread acceptance and application.

\section{PULMONARY REHABILITATION}

Pulmonary rehabilitation was an integral part of the care of the patients in the NETT, and whenever possible, patients were enrolled in rehabilitation at one of the primary NETT centers, however, a significant proportion $(65 \%)$ were treated at satellite centers with programs that were developed and supervised by the NETT center. ${ }^{27}$ There were 

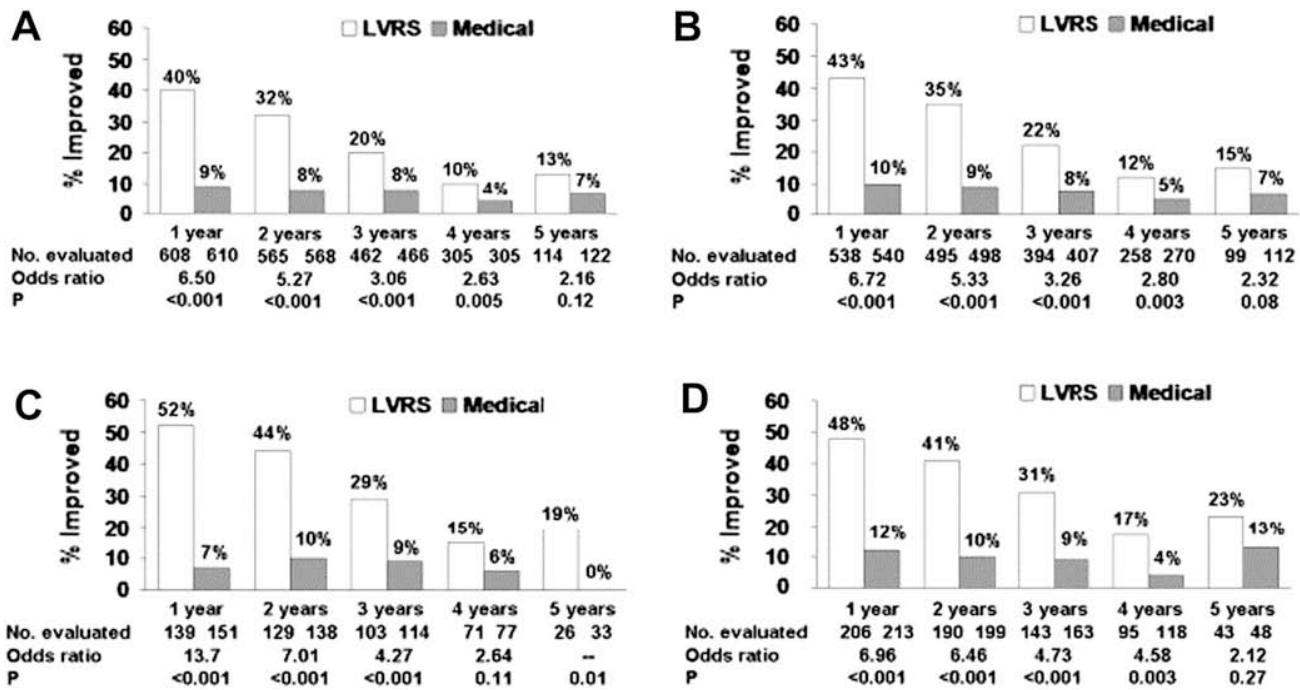

Fig. 6. Improvement in health-related quality of life (decrease in St. George 's Respiratory Questionnaire total score of $>8$ units below the patient 's postrehabilitation baseline) at 1, 2, 3, 4, and 5 years after randomization to lung volume reduction surgery (LVRS, open box) or medical treatment (filled box) for $(A)$ all patients and $(B-D)$ non-high-risk and upper-lobe-predominant subgroups of patients. Shown below each graph are the numbers of patients evaluated, the odds ratio for improvement (LVRS:Medical), and the Fisher exact $P$ value for difference in proportion improved. Patients who died or who did not complete the assessment were considered not improved. This is an intention-to-treat analysis. $(A)$ All patients $(n=1218)$. (B) Non-high-risk patients ( $n=1078)$. (C) Upper-lobe-predominant and low baseline exercise capacity $(n=290)$. (D) Upper-lobe-predominant and high exercise capacity $(n=419)$. (From Naunheim KS, Wood DE, Mohsenifar Z, et al. Long-term follow-up of patients receiving lung-volume-reduction surgery versus medical therapy for severe emphysema by the National Emphysema Treatment Trial research group. Ann Thorac Surg 2006;82:431-43; with permission.)

some patients who could not complete the course of rehabilitation therapy and thus proved too debilitated to undergo randomization. Conversely, a number of participants derived sufficient benefits that they were unwilling to undergo surgery and were also excluded from randomization. Of interest, although some patients experienced significant improvements in most measures of exercise capacity, dyspnea and quality of life after pulmonary rehabilitation, these changes did not translate into improved outcomes with surgery. Instead the subgroup with low exercise capacity achieved greater gains in functional status and survival benefit with LVRS indicating that patients who do not significantly improve after pulmonary rehabilitation may be more likely to benefit from LVRS. Overall, the NETT provided important validation of the role of pulmonary rehabilitation in preoperative evaluation and preparation for LVRS and also demonstrated that these results could be obtained at in the general community. ${ }^{27,28}$

\section{SUMMARY}

Surgery for severe emphysema involves a cohort of patients who are already at risk for increased perioperative morbidity and mortality. Through the careful screening and selection process, improved intraoperative techniques and rigorous attention to postoperative care, the NETT managed to yield acceptable improvements in survival and functional outcomes in this fragile patient cohort and these benefits were sustained over the long-term. Identification of the characteristics associated with a higher risk of death has provided tangible patient selection criteria for the ongoing application of LVRS. Because the NETT was such a large-scale study, the protocols that were developed had to be standardized across several centers. This produced reliable and reproducible standards for evaluation and treatment that can be applied to the surgical treatment of emphysema.

When considering these criteria, although individualized patient selection is important, only patients with upper-lobe predominant disease on chest CT and possibly those with non-upperlobe predominant disease who also have low baseline exercise capacity are appropriate candidates for LVRS. Expectedly, questions remain regarding the exact mechanism whereby the benefits derived from LVRS are obtained. Additionally, the benefit of LVRS in patients with heterogeneous but non-upper-lobe predominant disease remains to be further elucidated. 
In spite of the limitations of the study, the NETT, through a tremendous coordinated effort, provided valuable outcomes data, answered the pressing questions regarding lung volume reduction surgery that existed at the time, and provided valuable insight into other facets of emphysema physiology and management through direct observation.

Based on the NETT findings, in November 2003, CMS published criteria for expanded coverage for LVRS to include non-high-risk patients who demonstrated either upper-lobe predominant emphysema, or non-upper-lobe predominant emphysema and low baseline exercise capacity and who met the screening guidelines. ${ }^{29}$ This study not only provided data regarding the clinical efficacy of LRVS, but it was instrumental in determining health policy guidelines for the surgical management of emphysema.

\section{REFERENCES}

1. Deslauriers J. History of surgery for emphysema. Semin Thorac Cardiovasc Surg 1996;8:43-51.

2. Brantigan OC, Mueller E. Surgical treatment of pulmonary emphysema. Am Surg 1957;23:789-804.

3. Wakabayashi A, Brenner M, Kayaleh RA, et al. Thoracoscopic carbon dioxide laser treatment of bullous emphysema. Lancet 1991;337:881-3.

4. Wakabayashi A. Thoracoscopic laser pneumoplasty in the treatment of diffuse bullous emphysema. Ann Thorac Surg 1995;60:936-42.

5. Hazelrigg S, Boley T, Henkle J, et al. Thoracoscopic laser bullectomy: a prospective study with three-month results. J Thorac Cardiovasc Surg 1996;112:319-26.

6. Cooper JD, Trulock EP, Triantafillou AN, et al. Bilateral pneumectomy (volume reduction) for chronic obstructive pulmonary disease. J Thorac Cardiovasc Surg 1995;109:106-16.

7. Cooper JD, Patterson GA, Sundaresan RS, et al. Results of 150 consecutive bilateral lung volume reduction procedures in patients with severe emphysema. J Thorac Cardiovasc Surg 1996;112:1319-30.

8. Bingisser R, Zollinger A, Hauser M, et al. Bilateral volume reduction surgery for diffuse pulmonary emphysema by video-assisted thoracoscopy. J Thorac Cardiovasc Surg 1996;112:875-82.

9. Miller JI Jr, Lee RB, Mansour KA. Lung volume reduction surgery: lessons learned. Ann Thorac Surg 1996;61:1464-9.

10. McKenna RJ Jr, Brenner M, Fischel RJ, et al. Should lung volume reduction surgery be unilateral or bilateral? J Thorac Cardiovasc Surg 1996;112:1331-9.

11. Daniel TM, Chan BK, Bhaskar V, et al. Lung volume reduction surgery. Case selection, operative technique, and clinical results. Ann Surg 1996;223: 526-33.
12. Argenziano M, Moazami N, Thomashow B, et al. Extended indications for volume reduction pneumoplasty in advanced emphysema. Ann Thorac Cardiovasc Surg 1996;62:1588-97.

13. Wisser W, Tschernko E, Senbaklavaci O, et al. Functional improvement after volume reduction: sternotomy versus videoendoscopic approach. Ann Thorac Surg 1997;63:822-8.

14. Heath Care Financing Administration. Report to congress. Lung volume reduction surgery and Medicare coverage policy: implications of recently published evidence. Baltimore (MD): Heath Care Financing Administration; 1998.

15. National Emphysema Treatment Trial Research Group. Rationale and design of the National Emphysema Treatment Trial (NETT): a prospective randomized trial of lung volume reduction surgery. J Thorac Cardiovasc Surg 1999;118:518-28.

16. Lowdermilk GA, Keenan RJ, Landreneau RJ, et al. Comparison of clinical results for unilateral and bilateral thoracoscopic lung volume reduction. Ann Thorac Surg 2000;69:1670-4.

17. National Emphysema Treatment Trial Research Group. A randomized trial comparing lung-volumereduction surgery with medical therapy for severe emphysema. N Engl J Med 2003;348:2059-73.

18. NationalEmphysemaTreatment TrialResearch Group. Patients at high risk of death after lung-volume-reduction surgery. N Engl J Med 2001;345:1075-83.

19. Naunheim KS, Wood DE, Krasna MJ, et al. Predictors of operative mortality and cardiopulmonary morbidity in the National Emphysema Treatment Trial. J Thorac Cardiovasc Surg 2006;131:43-53.

20. National Emphysema Treatment Trial Research Group. Safety and efficacy of median sternotomy versus video-assisted thoracic surgery for lung volume reduction surgery. J Thorac Cardiovasc Surg 2004;127:1350-60.

21. Naunheim KS, Wood DE, Mohsenifar Z, et al. Long-term follow-up of patients receiving lung-volume-reduction surgery versus medical therapy for severe emphysema by the National Emphysema Treatment Trial research group. Ann Thorac Surg 2006;82:431-43.

22. National Center for Health Statistics. National Health Interview Survey 1994. Available at: http://www. cdc.gov/nchs/data/series/sr_10/sr10_193acc.pdf. Accessed May 9, 2008.

23. National Center for Health Statistics. National Health Interview Survey 2006. Available at: http://www. cdc.gov/nchs/data/series/sr_10/sr10_235.pdf. Accessed May 9, 2008.

24. Ramsey SD, Sullivan SD, Kaplan RM, et al. Economic analysis of lung volume reduction surgery as part of the National Emphysema Treatment Trial. Ann Thorac Surg 2001;71:995-1002.

25. National Emphysema Treatment Trial Research Group. Cost effectiveness of lung-volume-reduction 
surgery for patients with severe emphysema. N Engl J Med 2003;348:2092-102.

26. Ramsey SD, Shroyer AL, Sullivan SD, et al. Updated evaluation of the cost-effectiveness of lung volume reduction surgery. Chest 2007;131:823-32.

27. Ries AL, Make BJ, Lee SM, et al. The effects of pulmonary rehabilitation in the National Emphysema Treatment Trial. Chest 2005;128:3799-809.
28. Ries AL, Make BJ, Reilly JJ. Pulmonary rehabilitation in emphysema. Proc Am Thorac Soc 2008;5: 524-9.

29. Centers for Medicare and Medicaid Services. Revision 240.1 of pub. 100-03 Medicare national coverage determinations. Available at: http://www.cms.hhs.gov/ transmittals/downloads/R3NCD.pdf. Accessed May 17, 2008. 